\title{
Environmental efficiency measurement and the materials balance condition
}

\author{
Tim Coelli · Ludwig Lauwers • \\ Guido Van Huylenbroeck
}

Published online: 20 April 2007

(C) Springer Science+Business Media, LLC 2007

\begin{abstract}
The materials balance condition is a fundamental adding up condition, which essentially says that: "what goes in must come out". In this paper we argue that a number of the recently developed methods of incorporating pollution measures into standard productive efficiency models may be inconsistent with this fundamental condition. We propose an alternative method that involves the incorporation of the materials balance concept into the production model in a similar manner to which price information is normally incorporated. This produces a new environmental efficiency measure that can be decomposed into technical and allocative components, in a similar manner to the conventional cost efficiency decomposition. The approach is illustrated with the case of phosphorus emission on Belgian pig-finishing farms, using data envelopment analysis (DEA) methods. Our results indicate that a substantial proportion of nutrient pollution on these farms can be abated in a cost reducing manner.
\end{abstract}

Keywords Environmental efficiency - Materials balance condition $\cdot$ Nutrient pollution $\cdot$ Pig-finishing farms

\footnotetext{
T. Coelli $(\bowtie)$

Centre for Efficiency and Productivity Analysis, University of Queensland, Brisbane, QLD 4072, Australia

e-mail: t.coelli@economics.uq.edu.au

L. Lauwers $(\bowtie)$

Social Sciences Unit, Institute for Agricultural and Fisheries

Research, Merelbeke 9820, Belgium

e-mail: ludwig.lauwers@ilvo.vlaanderen.be

G. Van Huylenbroeck

Department of Agricultural Economics, Ghent University, Ghent 9000, Belgium

e-mail: Guido.vanhuylenbroeck@ugent.be
}

JEL Classifications $\quad$ B $21 \cdot$ C61 $\cdot$ D21 $\cdot$ Q12

\section{Introduction}

During the past two decades, the environmental side effects of economic activities have entered the core of public and political debate. In order to allow for better monitoring and evaluation of firms and their production processes, researchers have recognised the need to adjust traditional methods of productivity and efficiency analysis in order to integrate environmental concerns into the standard technical and economic efficiency measures.

Several attempts have already been made to integrate technical, economic and environmental performance measures (e.g., see review by Tyteca 1996 or Scheel 2001). Generally, these environmental performance measures are obtained by making adjustments to standard parametric and non-parametric efficiency analysis techniques. ${ }^{1}$ The majority of these studies have approached the problem by incorporating an extra pollution variable into the production model to be estimated, either as another input or as a weak disposable bad output (e.g., Färe et al. 1989; Ball et al. 1994; Piot-Lepetit and Vermersch 1998; Reinhard et al. 2000; Shaik et al. 2002).

In this study we introduce an alternative modelling approach that makes direct use of the materials balance concept and does not involve the introduction of an extra pollution variable into the production model. Our method has two principle advantages. First, it allows one to more clearly show that pollution reduction can be cost reducing in some instances (a point which has tended to be ignored

\footnotetext{
${ }^{1}$ See Coelli et al. (2005b) for an introductory treatment of these standard methods.
} 
in a number of past studies). Second, and most importantly, we show that past methods (which involve the introduction of pollution variables into the production technology) may suffer from certain problems when the materials balance condition is recognised, while the method we propose is shown to be consistent with this fundamental adding up condition.

The research that is reported in this paper was actually motivated by a practical problem. That is, how can one conduct an analysis of the efficiency of pig-finishing farms in Belgium that takes into account the problem of excess nutrient production on these farms? Intensive pig farming produces a lot of manure. In regions such as Flanders in Belgium, there are geographically concentrated groups of intensive farms that produce large amounts of manure that is difficult to dispose of in an economic and environmentally appropriate manner. This manure is rich in nutrients, such as phosphorus and nitrogen (in particular phosphorus), which leads to environmental problems, such as eutrophication (involving leaching into soil and water resources) and acidification (involving ammonia volatilisation which contributes to acid rain).

The standard way of calculating nutrient surplus in intensive livestock production is via the materials balance condition (e.g., see the analysis of nitrogen pollution in dairy farms in the Netherlands conducted by Reinhard and Thijssen 2000). The nutrient balance of a farm is calculated as the amount of nutrient that enters the farm in inputs minus the amount that leaves the farm bound up in useful output. Thus it is simply calculated as a linear function of the traditional input and output variables.

In this study, we argue that a number of the commonly used methods of incorporating pollution information into efficiency models-in particular methods involving the inclusion of a pollution variable as an input variable or (bad) output variable into a production technology-are inconsistent with the materials balance condition. In the following section we review some of these methods and show that the materials balance condition renders a number of them mathematically infeasible. ${ }^{2}$

Following this, in Sect. 3 we describe an alternative strategy (building upon the unpublished work of Lauwers et al. 1999) that uses standard optimisation methods to identify the emissions minimising input vector in a standard production model. This allows one to define an environmental efficiency measure that is consistent with the materials balance equation, and that can also be decomposed into technical and allocative components in a

\footnotetext{
${ }^{2}$ We have recently become aware of (via Prof. C.A.K. Lovell) two unpublished papers by Førsund (1998) and Murty and Russell (2002) which also express concerns regarding some of these models. However, neither of these papers suggest the solution outlined in this study.
}

similar way to the traditional cost efficiency decomposition method described in Farrell (1957). In Sect. 4 we use data envelopment analysis (DEA) methods to calculate these measures in an application involving data on Belgian pigfinishing farms. Summary and concluding comments are then provided in Sect. 5.

\section{Existing methods}

\subsection{Review of literature}

Various researchers have proposed performance indicators that seek to model the links between environmental pressure and economic or social activities. Tyteca (1996) gives a detailed literature review on the methods that have been used to measure the environmental performance of firms. $\mathrm{He}$ discusses various issues relevant to the development of environmental performance indicators, such as aggregation, normalisation, standardisation, relative or absolute measures and accounting issues, and finally, he stresses the potential of methods in the productive efficiency literature to deal with many of these issues.

The early literature linking pollution with productivity and efficiency measures mainly focussed upon the effects of pollution controls upon (macro) economic growth (Christainsen and Haveman 1981; Gollop and Roberts 1983; Färe et al. 1989). A few micro economic studies were conducted, such as Pittman (1981) and Pashigian (1984). However, these studies also focussed primarily upon the effects of pollution controls upon the production process, in particular the effect upon scale economies.

Pittman (1983), in an analysis of Wisconsin paper mills, was the first to attempt to incorporate environmental pollution into conventional productivity measures. This was done by making adjustments to the Caves et al. (1982) multilateral productivity index. Unlike traditional inputs and outputs, for which market prices are generally available, proxies were used for the undesirable output (i.e., pollution) prices in these pollution adjusted productivity indices. These proxies were derived from observed values, such as pollution taxes and marketable permits, or from shadow prices obtained from previous studies. This method implicitly assumes that pollution is costly, as discussed in the introduction section.

The first incorporation of environmental variables into firm-level efficiency analyses methods also assumed that pollution reduction would be costly. Färe et al. (1989), utilising the Pittman data, included pollution measures as bad outputs into a production model estimated using hyperbolic data envelopment analysis (DEA) methods. They introduced the notion of using the weak disposability concept to account for the fact that the bad outputs 
(pollution) cannot be freely disposed. Strong disposability implies that it is free of charge to dispose of unwanted inputs or outputs, weak disposability implies expensive disposal. Färe et al. (1989) suggested that comparing the (hyperbolic) productive efficiency measures of two models, one imposing strong disposability of all outputs on the technology and another preventing the strong disposability of undesirable outputs, yields information of the extent to which environmental regulations are binding. Moreover, they showed how it is possible to derive a producer-specific measure of potential output loss due to the lack of strong disposability. ${ }^{3}$ Färe et al. (1993) repeated this analysis using parametric output distance functions. This was done to allow them to more easily measure the shadow prices of the undesirable outputs.

A number of subsequent applied studies have used similar approaches in other industrial applications (e.g., Färe et al. 1996; Coggins and Swinton 1996; Chung et al. 1997; Färe et al. 2001) and also in agricultural applications involving nutrient pollution (e.g., Ball et al. 1994; PiotLepetit and Vermersch 1998; Reinhard and Thijssen 2000; Shaik et al. 2002; Asmild and Hougaard 2006). A selection of these studies is discussed below.

Färe et al. (1996) obtained environmental performance indicators for US fossil fuel-fired electric utilities, using input-orientated DEA methods containing "bad output" pollution variables, in a similar manner to the earlier hyperbolic DEA methods used in Färe et al. (1989). They decomposed overall productive efficiency into input efficiency and environmental efficiency. In fact for each firm, two input-oriented DEA models are run, the first allowing for the conventional proportional contraction of all inputs, the second having an extra constraint, which takes weak disposability of bad outputs into account. The environmental performance indicator was then defined as the ratio of the efficiency score obtained with the first model over the score obtained with the second model. The indicator takes values less than or equal to one, corresponding to environmental inefficiency or efficiency, respectively. Also Tyteca (1997) adapted the original Färe et al. (1989) and Ball et al. (1994) models with the explicit objective to

\footnotetext{
${ }^{3}$ It should be noted that the imposition of weak disposability (in " bad outputs") upon a production technology does not in itself impose the assumption that the bad outputs must be costly. This is because the dual shadow price for a bad output can in some cases be non-positive for some firms. However, in the Färe et al. (1989) study, the way in which the efficiency measures are calculated ensures that the relaxation of the environmental regulations (which is equated to the removal of the weak disposability assumption) can only lead to the production of more good output, because the weak disposability technology set is a subset of the strong disposability technology set. That is, it is not possible for this particular efficiency measurement approach to conclude that a reduction in pollution can coincide with increased output.
}

derive environmental efficiency scores, by measuring the degree to which the pollution variable could be reduced, with the quantities of inputs and outputs held fixed.

In an agricultural example, Reinhard et al. (2000) studied the effects of nitrogen pollution on intensive dairy farms in the Netherlands. They utilised DEA models in which a pollution variable is specified as an additional input variable (as opposed to the "bad output" approach discussed above). Their nitrogen pollution variable was calculated using a materials balance equation. They defined three different efficiency models. The first involved the contraction of the pollution input variable, holding the conventional inputs and output constant. The second was a generalisation of the classical Banker et al. (1984) outputoriented technical efficiency model, which allowed for the radial expansion of the outputs with the inputs (inclusive of the pollution input) held fixed. The third was the inputoriented formulation of the former. These models yielded three types of efficiency scores, (i) an environmental efficiency score; (ii) an output-oriented technical efficiency (TE) score; and (iii) an input-oriented $T E$ score.

\subsection{Applicability to the materials balance case}

In this section we argue that some of the above methods are likely to suffer from certain problems when the materials balance condition is applicable. First we define some notation.

Consider the situation where we have a firm that produces a vector of $m=1,2, \ldots, M$ outputs, $\mathbf{y} \in \mathbf{R}_{+}^{M}$, using a vector of $k=1,2, \ldots, K$ inputs, $\mathbf{x} \in \mathbf{R}_{+}^{K}$. The production activity also produces emission of possibly polluting substances as a by-product. The amount of emission is defined by the materials balance equation: $z=\mathbf{a}^{\prime} \mathbf{x}-\mathbf{b}^{\prime} \mathbf{y}$, where a and $\mathbf{b}$ are $(K \times 1$ and $M \times 1)$ vectors of known non-negative constants. ${ }^{4}$

First let us consider the original Färe et al. (1989) method. Their hyperbolic efficiency measure involves trying to find the largest scalar, $\lambda$, such that the scaled vector $(\lambda \mathbf{y}, \mathbf{x} / \lambda, \mathbf{z} / \lambda)$ is within the feasible production set. ${ }^{5}$ If we apply this scaling to the materials balance equation we obtain:

\footnotetext{
${ }^{4}$ Note that this allows for the possibility that some inputs (or outputs) could have zero amounts of the material of interest. For example, in the case of nitrogen pollution in intensive livestock farms, one would expect that the feed and livestock inputs would contain nitrogen but that labour and capital inputs would not.

${ }^{5}$ They define their production technology in a similar manner to that defined in Sect. 3 below, however they also include pollution as a "bad output" variable, where the technology is assumed to exhibit weak disposability in this variable.
} 
$z / \lambda=\mathbf{a}^{\prime} \mathbf{x} / \lambda-\mathbf{b}^{\prime} \mathbf{y} \lambda$

which implies:

$z-\mathbf{a}^{\prime} \mathbf{x}=-\mathbf{b}^{\prime} \mathbf{y} \lambda^{2}$

and hence $\lambda=1$ is the only positive value that can satisfy both the hyperbolic efficiency measure and the materials balance equation. ${ }^{6}$ Thus an interior point in the production technology (i.e., an inefficient point) is not feasible in this instance. This is not an attractive property. Hence the Färe et al. (1989) method is not a viable approach in this materials balance case.

A similar problem will arise with the Färe et al. (1996) approach. Their input orientated efficiency measure involves trying to find the largest scalar, $\lambda$, such that the scaled vector $(\mathbf{y}, \mathbf{x} / \lambda, z)$ is within the feasible production set. If we apply this scaling to the materials balance equation we obtain:

$z=\mathbf{a}^{\prime} \mathbf{x} / \lambda-\mathbf{b}^{\prime} \mathbf{y}$

which implies:

$\left(z+\mathbf{b}^{\prime} \mathbf{y}\right) \lambda=\mathbf{a}^{\prime} \mathbf{x}$

and thus $\lambda=1$ is again the only value that is mathematically feasible.

If we also apply a similar test to the three alternative efficiency measures used in Reinhard et al. (2000), namely $(\mathbf{y}, \mathbf{x}, \mathrm{z} / \lambda),(\mathbf{y} \lambda, \mathbf{x}, \mathrm{z})$ and $(\mathbf{y}, \mathbf{x} / \lambda, \mathrm{z} / \lambda)$, we come to the same conclusion. That is, the only efficiency score that is consistent with the materials balance condition is a value of one, implying that inefficient production is not permitted.

It is true that some of the above studies did not explicitly discuss a materials balance condition in their papers and hence one could argue that this particular problem is not relevant in those cases. However, it is difficult for one to conceptualise a production system in which a materials balance condition (e.g., for nitrogen or for carbon or for sulphur) does not exist. ${ }^{7}$

Some other researchers that are familiar with the typical biological nature of the nutrient emission problem in

\footnotetext{
${ }^{6}$ Except for trivial cases where, for example, all values in $\mathbf{a}$ and $\mathbf{b}$ are zero.

${ }^{7}$ Note that in some industrial applications, some of the existing methods may still be consistent with the materials balance condition. For example, in the case of coal-fired electricity generation, where the electricity output does not contain sulphur, we would have a situation where $\mathbf{b}=0$. In this instance, efficiency measures that augment output $(\mathbf{y} \lambda, \mathbf{x}, \mathbf{z})$ or contract input and pollution simultaneously $(\mathbf{y}, \mathbf{x} / \lambda, \mathrm{z} / \lambda)$ may still conform with the materials balance principle. However, a hyperbolic measure, such as $(\mathbf{y} \lambda, \mathbf{x} / \lambda, \mathbf{z} / \lambda)$, is likely to be problematic.
}

agriculture have also begun to question the applicability of some of these methods. For example, Piot-Lepetit et al. (1997) observed that one should be able to reduce the external impacts of nutrient pollution through reducing persistent inefficient levels of input use. Additionally, Reinhard and Thijssen (2000) discuss the notion of an environmentally optimal allocation of inputs, determined by their nitrogen contents. They used a shadow cost system in which shadow prices can deviate from the market prices. Similar to price distortion factors, they calculated nitrogen distortion factors. That is, the degree to which the input mixes deviate from those that would minimise nutrient pollution. However, they do not attempt to use this model for measuring and decomposing environmental efficiency indices in the manner we outline in the next section.

\section{An alternative modelling strategy}

\subsection{Proposed efficiency measures}

In this section we consider, as above, a firm that produces a vector of $m=1,2, \ldots, M$ outputs, $\mathbf{y} \in \mathbf{R}_{+}^{M}$, using a vector of $k=1,2, \ldots, K$ inputs, $\mathbf{x} \in \mathbf{R}_{+}^{K}$. The feasible production set, $T$, is defined as:

$T=\left\{\langle\mathbf{y}, \mathbf{x}\rangle \in \mathbf{R}_{+}^{M+K} \mid \mathbf{x}\right.$ can produce $\left.\mathbf{y}\right\}$,

where the production technology is assumed to be convex and non-increasing in inputs, non-decreasing in outputs, and exhibits strong disposability in inputs and outputs. ${ }^{8}$

We define a surplus measure, $z \in \mathbf{R}_{+}$, that is calculated using a material balance equation, which is a linear function of the output and input vectors. That is:

$z=\mathbf{a}^{\prime} \mathbf{x}-\mathbf{b}^{\prime} \mathbf{y}$

where $\mathbf{a}$ and $\mathbf{b}$ are $(K \times 1$ and $M \times 1)$ vectors of known non-negative constants. ${ }^{9}$

Given that a particular amount of output is to be produced, one question that could be of interest is: What combination of inputs would result in the lowest possible quantity of surplus (i.e., pollution), for a specified amount of output? One can approach this question of surplus minimisation in an analogous manner to that of cost minimisation. ${ }^{10}$ First we note that since the output vector $(\mathbf{y})$ is fixed,

\footnotetext{
${ }^{8}$ See Coelli et al. (2005b) for further discussion of these properties.

${ }^{9}$ Note that we have called these items "surplus measures" as opposed to "emission measures" or "pollution measures". This distinction is important, as will become apparent when we discuss abatement strategies later in this section. Furthermore, note that the possibility of two or more emission types is also considered later in this section.

${ }^{10}$ For example, see Färe et al. (1994).
} 
the nutrient surplus ( $\mathrm{z}=\mathbf{a}^{\prime} \mathbf{x}-\mathbf{b}^{\prime} \mathbf{y}$ ) will be minimised when the aggregate nutrient content of the inputs $\left(N=\mathbf{a}^{\prime} \mathbf{x}\right)$ is minimised. Thus, given a vector of $k=1,2, \ldots, K$ nutrient contents, $\mathbf{a} \in \mathbf{R}_{+}^{K}$, one can define the minimum nutrients associated with producing a particular output vector as:

$N(\mathbf{y}, \mathbf{a})=\min _{\mathbf{x}}\left\{\mathbf{a}^{\prime} \mathbf{x} \mid\langle\mathbf{x}, \mathbf{y}\rangle \in T\right\}$.

The input vector that involves minimum nutrients (which implies minimum nutrient surplus and hence the best environmental result) is denoted by $\mathbf{x}_{e}$, where the minimum nutrient quantity equals $\mathbf{a}^{\prime} \mathbf{x}_{e}$. Furthermore, the nutrient quantity at the observed input vector is equal to $\mathbf{a}^{\prime} \mathbf{x}$.

In the event that the observed input vector is not located on the boundary of the technology set, one can also identify the Farrell (1957) technically efficient input vector, $\mathbf{x}_{t}$, by proportionally shrinking the observed input vector until it is projected onto the boundary of the technology set. That is, by solving the optimisation problem:

$T E(\mathbf{y}, \mathbf{x})=\min _{\theta}\{\theta \mid\langle\theta \mathbf{x}, \mathbf{y}\rangle \in T\}$,

where $\theta$ is a scalar that takes a value between zero and one. The technically efficient input vector is calculated as $\mathbf{x}_{t}=\theta \mathbf{x}$, and the corresponding nutrient quantity is $\mathbf{a}^{\prime} \mathbf{x}_{t}$.

These three input vectors can be illustrated on a simple diagram for the case where there are only two input variables. This is done in Fig. 1, where the nutrient content information (per unit of each input) is reflected in the slopes of the iso-nutrient lines (in an analogous manner to iso-cost lines in the cost minimisation case). Note that the iso-nutrient line in this simple two input case is

$N=a_{1} x_{1}+a_{2} x_{2}$,

which after rearrangement becomes:

$x_{1}=\frac{N}{a_{1}}-\frac{a_{2}}{a_{1}} x_{2}$.

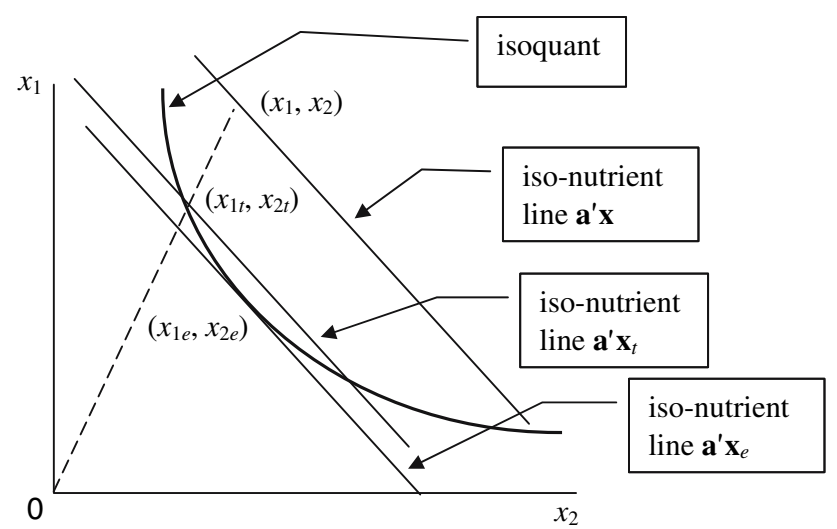

Fig. 1 Nutrient minimisation
Thus the iso-nutrient lines in Fig. 1 have intercepts equal to $N / a_{1}$ and (identical) slopes equal to the negative of the nutrient content ratio. Clearly the iso-nutrient line that passes through the observed point $\left(x_{1}, x_{2}\right)$ has a larger intercept than that line which passes through the nutrient minimising point $\left(x_{1 e}, x_{2 e}\right)$, implying that it must also be associated with a larger amount of nutrient $(N)$. Similarly, the iso-nutrient line that passes through the technically efficiency point $\left(x_{1 t}, x_{2 t}\right)$ must have an intercept (and hence nutrient) that lies between these two levels.

Next we define our new environmental efficiency measures. The environmental efficiency $(E E)$ of a firm equals the ratio of minimum nutrients over observed nutrients:

$E E=\mathbf{a}^{\prime} \mathbf{x}_{e} / \mathbf{a}^{\prime} \mathbf{x}$

This will take a value between zero and one, with a value of one indicating full environmental efficiency. That is, given the available technology, it is not possible to produce the specified amount of output with a smaller nutrient surplus.

One can decompose $E E$ into two components: that part due to technical efficiency $(T E)$ and that part due to environmental allocative efficiency $(E A E)$, where

$T E=\mathbf{a}^{\prime} \mathbf{x}_{t} / \mathbf{a}^{\prime} \mathbf{x}=\mathbf{a}^{\prime}\left(\theta \mathbf{x}_{t}\right) / \mathbf{a}^{\prime} \mathbf{x}=\theta$,

and

$E A E=\mathbf{a}^{\prime} \mathbf{x}_{e} / \mathbf{a}^{\prime} \mathbf{x}_{t}$,

where $E A E$ essentially relates to having the correct input mix, given observed nutrient content relativities, while $T E$ relates to operation on the boundary of the technology (i.e., the production frontier). All three efficiency measures take a value between zero and one, with a value of one indicating full efficiency. We also note that the three measures are related, such that

$E E=T E \times E A E$.

If one had access to information on the input price levels, one could also follow a similar procedure and identify the cost-minimising data point, and obtain cost efficiency (CE) measures, which could be then decomposed in the familiar technical efficiency and allocative efficiency (AE) measures.

In Fig. 2 we plot both the iso-nutrient and iso-cost lines. The notation $\mathbf{w} \in \mathbf{R}_{+}^{K}$ is used to represent the input price vector and $\mathbf{x}_{c}$ to denote the cost-minimising input quantity vector. When this price information is available, one can also identify two additional quantities of interest. That is, the cost of the nutrient minimising input bundle, $\mathbf{w}^{\prime} \mathbf{x}_{e}$, and the nutrients corresponding to the cost minimising input 


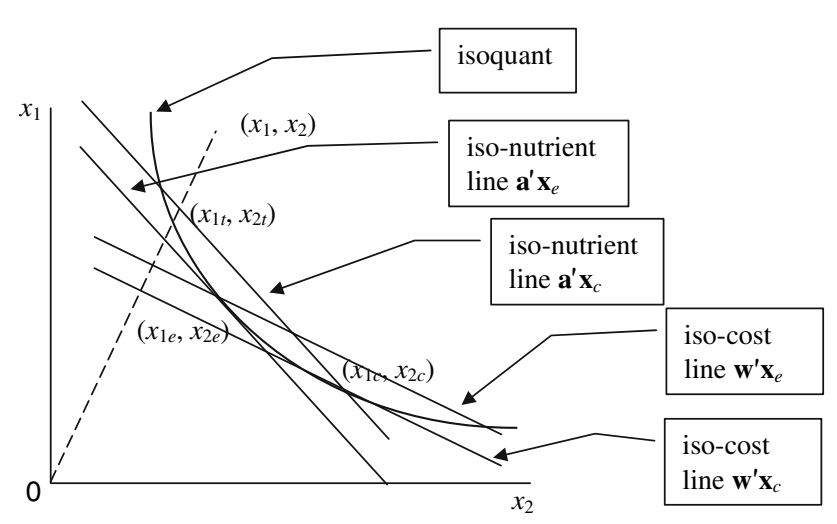

Fig. 2 Costs and benefits of nutrient minimisation

bundle, $\mathbf{a}^{\prime} \mathbf{x}_{c}$. Using the first of these measures we can identify the cost associated with moving from the cost minimising point to the nutrient minimising point, $\left(\mathbf{w}^{\prime} \mathbf{x}_{e}-\mathbf{w}^{\prime} \mathbf{x}_{c}\right)$. This could be interpreted as the shadow cost of the nutrient reduction. However, if alternative cheaper abatement strategies, such as manure transportation, were available, this measure would overstate the shadow cost.

The second of these new measures, $\mathbf{a}^{\prime} \mathbf{x}_{c}$, can be used to identify the nutrient surplus consequences associated with movement from the nutrient minimising point to the cost minimising point, $\left(\mathbf{a}^{\prime} \mathbf{x}_{c}-\mathbf{a}^{\prime} \mathbf{x}_{e}\right.$.) This provides a measure of the surplus reduction that could be achieved if the relative prices of these inputs are adjusted (e.g., via taxation) to encourage nutrient minimisation. Obviously, the two optimal points will coincide when the input price relativities are adjusted so that $\mathbf{w}=\alpha \mathbf{a}$, where $\alpha$ is a positive scalar. ${ }^{11}$

In the example provided in Fig. 2, the technically efficiency point is located to the left of both the optimal points. Hence, a movement along the isoquant from the technically efficient point to the nutrient minimising point results in a reduction in costs in this instance. This need not always be the case. An improvement in $E E$ could be associated with either an increase or a decrease in $C E$. If the improvement in $E E$ is due to an improvement in $T E$ then $C E$ will improve. However, if it is due to an improvement in $E A E$ then it could result in a rise or fall in $C E$, depending upon whether the movement is towards or away from the cost minimising point.

\subsection{Some generalisations}

\subsubsection{Multiple pollutants}

The above method can be generalised to the case of two or more pollutants. One could use the method to identify the

\footnotetext{
$\overline{11}$ This nutrient reduction only relates to that which is a consequence of changing the input mix used. Explicit abatement activities, such as manure treatment, may allow further reductions in nutrient emissions.
}

surplus minimising point for each pollutant individually. For example, one could identify one point for phosphorus and one point for nitrogen in an agricultural application. Alternatively, if one wishes to identify an "aggregate" surplus minimising point, this would require the specification of weights (or relative prices) for the two (or more) types of pollution. For example, in the case where there are two pollutants, two inputs and one output, the two balance equations could be:

$z_{1}=a_{11} x_{1}+a_{21} x_{2}-b_{1} y$,

and

$z_{2}=a_{12} x_{1}+a_{22} x_{2}-b_{2} y$

and if the chosen weights were $v_{1}$ and $v_{2}$, the aggregate balance equation would become:

$$
\begin{aligned}
\left(v_{1} z_{1}+v_{2} z_{2}\right)= & \left(v_{1} a_{11}+v_{2} a_{12}\right) x_{1}+\left(v_{1} a_{21}+v_{2} a_{22}\right) x_{2} \\
& -\left(v_{1} b_{1}+v_{2} b_{2}\right) y
\end{aligned}
$$

or equivalently

$z^{*}=a_{1}^{*} x_{1}+a_{2}^{*} x_{2}-b^{*} y$

and the method would then proceed normally. ${ }^{12}$

\subsubsection{Including the social costs of the pollutants}

In our earlier discussion we identified two optimal points on the production surface: the cost minimising point and the nutrient minimising point. If the price of pollution was known (e.g., the social cost) then one could use this information to identify a new comprehensive cost (CC) minimising optimal point that takes into account both the private costs of the firm and the social costs of pollution. If the per unit price of pollution, $u$, is given then the standard cost minimisation problem

$C(\mathbf{y}, \mathbf{w})=\min _{\mathbf{x}}\left\{\mathbf{w}^{\prime} \mathbf{x} \mid\langle\mathbf{x}, \mathbf{y}\rangle \in T\right\}$.

can be combined with that from equation 3 to form:

$C C(\mathbf{y}, \mathbf{w})=\min _{\mathbf{x}}\left\{\mathbf{w}^{\prime} \mathbf{x}+u\left(\mathbf{a}^{\prime} \mathbf{x}\right) \mid\langle\mathbf{x}, \mathbf{y}\rangle \in T\right\}$.

Given that $\mathbf{w}^{\prime} \mathbf{x}+u\left(\mathbf{a}^{\prime} \mathbf{x}\right)=(\mathbf{w}+u \mathbf{a})^{\prime} \mathbf{x}$, it is clear that this is equivalent to a standard cost minimisation problem where the prices of the inputs have been adjusted by a factor equal to their pollution content multiplied by the

\footnotetext{
${ }^{12}$ In the eutrophication case, the choice of weights is straightforward: the eutrofying power of phosphorus is ten times more than that of nitrogen.
} 
price of pollution. This framework could be used by policy makers in various ways. For example, to assess the impact of possible pollution taxes upon the levels of pollution in various industries.

\subsubsection{Pollution abatement activities}

In the above model, we have assumed that the production process does not involve any form of specific (input consuming) pollution abatement activity, such as the transport of manure to other farms for use as a (appropriately regulated) fertiliser, or the installation of scrubbers in the smoke stacks of electricity generation plants. Pollution abatement of this type generally implies the need for the use of extra inputs, such as extra capital in the scrubbers case and extra labour, fuel and transport equipment in the manure transport case. ${ }^{13}$

In this instance it could seem logical for one to include a pollution quantity variable as an explicit production variable (input or bad output) into the production model. However, we would encounter two problems associated with the materials balance condition if this was done. The first is that the materials balance condition will produce an upward biased estimate of the pollution quantity variable unless one can adjust it in some way by subtracting the amount of pollution that is abated by these particular activities. The second problem is that the inclusion of this pollution variable will mean that the problems discussed earlier, regarding the mathematical impossibility of inefficient data points, will return.

One possible solution to these problems is to include an extra "abatement output" variable, such as "environmentally approved manure" or "scrubbed materials", into the production model, in association with the above materials balance analysis of environmental efficiency. It should be emphasised that this would be a good output variable not a bad output variable. In the case of nutrients in manure, one can measure this variable directly. In the case of electricity generation, if one has data on pollution that is emitted, one could calculate the amount scrubbed by subtracting the pollution measure from the surplus calculation.

With this type of model formulation one can then accommodate four different pollution reduction strategies:

(1) improvements in technical efficiency;

(2) improvements in environmental allocative efficiency;

(3) employment of extra inputs for pollution abatement; and

(4) output reduction,

\footnotetext{
${ }^{13}$ Note that in the case of manure, the installation of manure treatment equipment is also an option.
}

in a comprehensive and mathematically feasible manner. Note that option 1 is cost reducing; option 2 can be either cost reducing or increasing; option 3 will be costly; while option 4 will reduce profits (if the production of the marginal unit of output is profitable).

\section{An empirical illustration using Belgian pig-finishing farms}

Intensive pig farming is one of the main causes of nutrient surplus problems in intensive livestock regions such as Flanders (Belgium), the Netherlands and Brittany (France). The high density of production in these regions results in a volume of nutrient excretion far higher than is needed for fertilisation. The resulting nutrient surplus leads to environmental problems such as eutrophication and acidification. Phosphorus (P) is the most important nutrient in question. One $\mathrm{kg}$ of $\mathrm{P}$ has the same eutrophying power as $0.1 \mathrm{~kg}$ of nitrogen $(\mathrm{N})$. Expressed in phosphate, the total production from livestock in Flanders (where almost the entire Belgian pig-finishing activity is located) is estimated at 85 million $\mathrm{kg} \mathrm{P}_{2} \mathrm{O}_{5}$ per year (of which more than half comes from pigs), whereas fertilisation limits restrict the environmentally acceptable disposal on agricultural land to about 60 million $\mathrm{kg}_{2} \mathrm{O}_{5}$ per year. Strong competition for this disposal room leads to disposal costs of about 3 euro per $\mathrm{kg} \mathrm{P}_{2} \mathrm{O}_{5}$. The costs of manure treatment are about double this amount. Economically feasible solutions for the remaining 25 million $\mathrm{kg}_{2} \mathrm{O}_{5}$ per year are still yet to be found.

\subsection{Data description}

The data used for this research consist of a representative cross-section of 183 Belgian pig finishing farms in the accounting year 1996-1997. This data is taken from the Belgian Farm Accountancy Data Network, FADN (the official Belgian network being part of the European FADN, see http://www.europa.eu.int/comm/agriculture/rica). The main inputs used in pig finishing, in terms of their contribution to total costs, are piglets and feed. Labour and capital are minor inputs. ${ }^{14}$ The nutrients embodied in two of the inputs, piglets and feed, are not entirely recuperated in the marketable output, pig meat (i.e., pork), with the balance being excreted in manure.

Preliminary econometric analysis of the available data indicates that the capital expenses and other expenses (mostly labour) variables are not significant explanators of output. Moreover, this econometric analysis indicates that

\footnotetext{
${ }^{14}$ See Coelli et al. (2005a) for a working paper version of this paper where additional detail, including descriptive statistics, is provided.
} 
the technology exhibits constant returns to scale (CRS). ${ }^{15}$ Hence, in the empirical analysis reported in this paper, we have a production model with one output (pig meat), two inputs (piglet meat and feed) and a CRS technology.

\subsection{DEA analysis}

The $E E$ measure described in Sect. 3 were obtained using a DEA program similar to the cost-minimising DEA program described in Coelli et al. (2005b). That is ${ }^{16}$

$$
\begin{gathered}
\min _{\lambda, x i e}\left(\mathbf{a}_{i}^{\prime} \mathbf{x}_{i}^{e}\right), \\
\text { st } \quad \mathbf{y}_{i}+\mathbf{Y} \lambda \geq \mathbf{0}, \\
\mathbf{x}_{i}^{e}-\mathbf{X} \lambda \geq \mathbf{0}, \\
\lambda \geq \mathbf{0},
\end{gathered}
$$

where the vectors $\mathbf{x}_{i}$ and $\mathbf{y}_{i}$ represent (respectively) data on the $K$ inputs and $M$ outputs of the $i$-th farm; the $K \times I$ input matrix, $\mathbf{X}$, and the $M \times I$ output matrix, $\mathbf{Y}$, represent the data for all $I$ farms in the sample; and $\lambda$ is a $I \times 1$ vector of constants. Furthermore, cost efficiency $(C E)$ and technical efficiency $(A E)$ scores were calculated using the standard DEA programs described in Coelli et al. (2005b).

The DEA results are summarised in Table 1 . The mean technical efficiency (TE) score of 0.897 suggests that the average farm should be able to produce their current output with $10.3 \%$ fewer inputs. The mean environmental efficiency $(E E)$ score of 0.843 indicates that the average farm should be able to produce their current output with an input bundle that contains $15.7 \%$ less phosphate. ${ }^{17}$ Approximately two thirds of this $E E$ is due to technical inefficiency (operating below the production frontier) and one third is due to environmental allocative inefficiency $(E A E)$ (i.e., using a sub-optimal mix of feed and piglets). The mean EAE score was 0.940 .

\footnotetext{
${ }^{15}$ We were unable to reject the null hypothesis of CRS at the $10 \%$ level of significance. These econometric results are available from the authors on request. Note also that we also repeated our DEA analysis with a variable returns to scale (VRS) technology and found that mean scale efficiency was 0.983 and hence that the empirical results changed very little between CRS and VRS.

16 The phosphorus contents of pig meat, feed and piglet meat (in $\mathrm{kg}$ per $\mathrm{kg}$ ) are $0.0117,0.0124$ and 0.0117 , respectively. These values were obtained from CAE (1998).

${ }^{17}$ It should be stressed that these farm-level environmental efficiency scores should not be directly interpreted as corresponding to a particular amount of environmental damage, since some farms may have locational characteristics (e.g., soil type and topography) such that the resulting environmental damage to waterways is less than that for other farms. Furthermore, some farms could be engaging in pollution abatement activities (such as manure treatment and or transport). Thus an extension of the model to incorporate this abatement output variable (as discussed in the previous section) could be of interest, if data on abatement activity was readily available.
}

Table 1 DEA results

\begin{tabular}{lcccc}
\hline Efficiency measure & Mean & Stdev. & Min & Max \\
\hline Technical efficiency $(T E)$ & 0.897 & 0.055 & 0.727 & 1.000 \\
$\begin{array}{l}\text { Environmental allocative efficiency } \\
\quad(E A E=E E / T E)\end{array}$ & 0.940 & 0.046 & 0.763 & 1.000 \\
Environmental efficiency $(E E)$ & 0.843 & 0.065 & 0.670 & 1.000 \\
Allocative efficiency $(A E=C E / T E)$ & 0.985 & 0.021 & 0.877 & 1.000 \\
Cost efficiency $(C E)$ & 0.883 & 0.057 & 0.722 & 1.000 \\
\hline
\end{tabular}

Mean cost efficiency $(C E)$ is 0.883 , which suggests that the average farm could reduce costs by $11.7 \%$ and still produce the same output. This cost inefficiency is primarily due to technical inefficiency. The mean $A E$ score is quite high, at 0.985 . This suggests that most farms are using an input mix that approximates the cost minimising input mix. This high mean $A E$ score is unusual but not surprising for this particular industry. It is most likely due to the fact that the technology is well known, the production environment is controlled (mostly under cover), and the advice given by agricultural extension advisers is widely known and applied.

What are the implications of these results if we extrapolate them to the industry level? Given that we know that this sample is representative of the population and given that the efficiency levels are essentially uncorrelated with farm size ${ }^{18}$ we make the following observations. First, we note that the above $E E$ scores are expressed as a percentage of the total phosphorus input on the farm. The impact on phosphorus surplus itself will hence be larger. Indeed, pig finishing in Flanders (based on livestock statistics of 1997 in order to remain coherent with the data in this study) is responsible for a surplus of 24.5 million $\mathrm{kg}$ of $\mathrm{P}_{2} \mathrm{O}_{5}$ per year (5.7 $\mathrm{kg}$ per average finished pig per year multiplied by 4.3 million pigs). This surplus results from 38.1 million $\mathrm{kg}$ of $\mathrm{P}_{2} \mathrm{O}_{5}$ per year from inputs (feed and piglets) and 13.6 million $\mathrm{kg}$ of $\mathrm{P}_{2} \mathrm{O}_{5}$ per year of output (pig meat).

If the estimate of $15.7 \%$ average environmental inefficiency was applicable to the whole pig-finishing industry, it suggests that approximately 5.98 million $\mathrm{kg}_{2} \mathrm{O}_{5}$ input could be avoided if all farms were to achieve environmental efficiency. Expressed over the original surplus amount, this nutrient saving (with output fixed) suggests a surplus reduction of approximately one quarter.

This estimated potential for phosphorus surplus reduction in the pig farming analysis is a substantial amount, for which one has no need to find extra and expensive new technologies for pollution reduction. However, one must recognise that there is likely to be a cost associated with operation at the emission minimising point. On the one

\footnotetext{
${ }^{18}$ The correlation coefficient between TE and farm size (measured in APF) is 0.02 and is not significantly different from zero at any standard level of significance.
} 


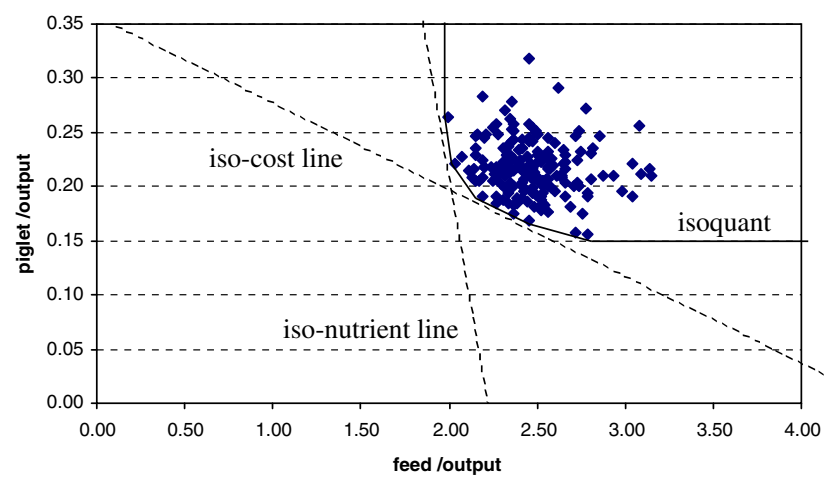

Fig. 3 DEA analysis of pig-finishing data

hand, improving $T E$ will both reduce pollution and reduce cost, but as noted earlier, improving $E A E$ is likely to result in increased cost in some (if not many) cases, as one moves away from the cost-minimising point.

In order to consider this issue further, we have plotted our sample data in Fig. 3. Given that we have one output, two inputs and a CRS technology, we can represent our DEA analysis in this two dimensional diagram. The sample data, the DEA frontier (i.e., unit isoquant) and the iso-cost and iso-nutrient lines are presented in Fig. 3. ${ }^{19}$

Two optimal points are identified in Fig. 3. The nutrient minimising optimal point is 2.038 feed $\mathrm{kg}$ per pig meat $\mathrm{kg}$ and 0.221 piglet meat $\mathrm{kg}$ per pig meat $\mathrm{kg}$. The cost minimising optimal point is 2.187 feed $\mathrm{kg}$ per pig meat $\mathrm{kg}$ and 0.1903 piglet meat $\mathrm{kg}$ per pig meat $\mathrm{kg}$. The costs at these two points (using the mean prices from the sample) are approximately 0.937 and 0.896 euros, respectively. This suggests that movement from the nutrient minimising point to the cost minimising point will reduce unit costs by $4.6 \%$. The nutrients input at these two points are 27.84 and $29.34 \mathrm{~g}$, respectively. This suggests that movement from the cost minimising point to the nutrient minimising point will reduce nutrient inputs by $5.3 \%$.

This information can also be used to construct a shadow cost estimate. The shadow cost of this nutrient surplus reduction is $(0.937-0.896) /(29.34-27.84)=0.027$ euros per gram or 27 euros per $\mathrm{kg}$. This is larger than alternative abatement strategies, such as manure treatment, which is approximately six euros per $\mathrm{kg} .{ }^{20}$ Hence, in this case the

\footnotetext{
${ }^{19}$ Note that the iso-cost line is that which corresponds to the mean prices from Table 1 . This is done because the diagram would become too messy if we attempted to plot the iso-cost lines of each farm in the sample (prices vary to some extent from farm to farm).

${ }^{20}$ This estimate is only provided for illustrative purposes at this stage, given that DEA frontiers can be susceptible to measurement errors in input and output measures. In future work we plan to repeat this analysis using stochastic frontier methods (see Coelli et al. 2005a) to see how robust these results are to the use of a frontier estimation methodology that explicitly attempts to accommodate data noise.
}

advice to the farmer would most likely be to adjust the input mix so as to reach this cost minimising point, but not attempt to move further to the nutrient minimising point, because the alternative abatement strategies are less costly.

\section{Conclusions}

A new method of measuring the environmental efficiency of firms is proposed that involves the identification of nutrient minimising input vectors in the context of a standard production model. The method is applicable when pollution is calculated using a materials balance equation, and can be calculated using traditional data envelopment analysis (DEA) methods. The new measure has the additional advantage that it can also be decomposed into technical and allocative components.

Discussion of some previously proposed methods indicates that they have certain shortcomings when the materials balance condition is applicable. In contrast to the conventional environmental efficiency methods, which model pollutants as weakly disposable outputs or as environmentally detrimental inputs and imply a costly disposal or control of these pollutants, the new method allows, up to a certain pollution abatement level, for negative abatement costs. Above that level, additional technologies for pollution reduction or bad output disposal will remain necessary, which may then justify the modelling of this type of pollution abatement activity as an extra output variable.

With regards to the Belgian pig-finishing industry that featured in the empirical illustration, this study suggests that substantial potential exists for nutrient pollution reduction via efficiency improvements, which are cost reducing as opposed to cost increasing. Given that pig production is a conditioned indoor activity, which is highly manageable and does not suffer (like most agricultural activities) from persistent inefficiencies due to quasi-fixed environmental conditions, it can be argued that the degree of inefficiency measured in this study provides a realistic measure of the potential improvement. Furthermore, given the observation that current abatement strategies in Flanders rely almost exclusively on new technologies or production processes, this knowledge may be of significant benefit to this industry.

Acknowledgements We are grateful to Knox Lovell and three anonymous referees for a number of useful comments on an earlier draft. The authors take responsibility for any errors that may remain.

\section{References}

Asmild M, Hougaard JL (2006) Economic and environmental efficiency of Danish pig farms. Agricultural Economics $35: 171-181$ 
Ball VE, Lovell CAK, Nehring RF, Somwaru A (1994) Incorporating undesirable outputs into models of production: an application to US agriculture. Cahiers d'Economie et Sociologie Rurales 31:59-74

Banker RD, Charnes A, Cooper WW (1984) Some models for estimating technical and scale inefficiencies in data envelopment analysis. Manage Sci 30:1078-1092

CAE (1998) Technische en economische resultaten van de varkenshouderij op bedrijven uit het CLE-Boekhoudnet, boekjaar 19961997 [Technical and economic performance of pig production on farms of the CAE Farm Accountancy Data Network, bookkeeping year 1996-1997], Centre for Agricultural Economics, Brussels

Caves DW, Christensen LR, Diewert WF (1982) Multilateral comparisons of output, input and productivity using superlative index numbers. Econ J 92:73-86

Christainsen GB, Haveman RH (1981) The contribution of environmental regulations to the slowdown in economic growth. J Environ Econ Manage 8:381-390

Chung YH, Färe R, Grosskopf S (1997) Productivity and undesirable outputs: a directional distance function approach. J Environ Manage 51:229-240

Coelli TJ, Lauwers L, van Huylenbroeck G (2005a) Formulation of technical, economic and environmental efficiency measures that are consistent with the materials balance condition, CEPA Working Papers, No. 6/2005, School of Economics, University of Queensland

Coelli TJ, Prasada Rao DS, O’Donnell CJ, Battese GE (2005b) An introduction to efficiency and productivity analysis. 2nd edn, Springer, New York

Coggins JS, Swinton JR (1996) The price of pollution: a dual approach to valuing $\mathrm{SO}_{2}$ allowances. $\mathrm{J}$ Environ Econ Manage 30:58-72

Färe R, Grosskopf S, Lovell CAK (1994) Production frontiers. Cambridge University Press, Cambridge

Färe R, Grosskopf S, Lovell CAK, Pasurka C (1989) Multilateral productivity comparisons when some outputs are undesirable: a non-parametric approach. Rev Econ Statis 71:90-98

Färe R, Grosskopf S, Lovell CAK, Yaisawarng S (1993) Derivation of shadow prices for undesirable outputs: a distance function approach. Rev Econ Statis 75:374-380

Färe R, Grosskopf S, Pasurka C (1989) The effect of environmental regulations on the efficiency of electric utilities: 1969 versus 1975. Appl Econ 21:225-235

Färe R, Grosskopf S, Pasurka CA (2001) Accounting for air pollution in measures of state manufacturing growth. J Regional Sci 41:381-409

Färe R, Grosskopf S, Tyteca D (1996) An activity analysis model of the environmental performance of firms - application to fossilfuel-fired electric utilities. Ecol Econ 18:161-175
Farrell MJ (1957) The measurement of productive efficiency. J Royal Statis Soc 120:253-281

Førsund F (1998) Pollution modelling and multiple-output production theory mimeo, Department of Economics, University of Oslo (contact: finn.forsund@econ.uio.no).

Gollop F, Roberts MJ (1983) Environmental regulations and productivity growth: the case of fossil-fuelled electric power generation. J Polit Econ 91:654-674

Lauwers L, Van Huylenbroeck G, Rogiers G (1999) Technical, economic and environmental efficiency analysis of pig fattening farms, Poster presentation at the 9th European Congress of Agricultural Economists, Warschau, Polen, August 24th-28th, 1999

Murty S, Russell RR (2002) On modeling pollution-generating technologies. mimeo, Department of Economics, University of California Riverside, (http://www.economics.ucr.edu/people/russell/02-14.pdf)

Pashigian BP (1984) The effect of environmental regulation on optimal plant size and factor shares. J Law Econ 27:1-28

Piot-Lepetit I, Vermersch D (1998) Pricing organic nitrogen under the weak disposability assumption: an application to the French pig sector. J Agric Econ 49:85-99

Piot-Lepetit I, Vermersch D, Weaver RD (1997) Agriculture's environmental externalities: DEA evidence for French agriculture. Appl Econ 29:331-338

Pittman RW (1981) Issues in pollution control: interplant cost differences and economies of scale. Land Econ 57:1-17

Pittman RW (1983) Multilateral productivity comparisons with undesirable outputs. Econ J 93:883-891

Reinhard S, Lovell CAK, Thijssen G (2000) Environmental efficiency with multiple environmentally detrimental variables; estimated with SFA and DEA. Eur J Oper Res 121:287-303

Reinhard S, Thijssen G (2000) Nitrogen efficiency of Dutch dairy farms: a shadow cost system approach. Eur Rev Agric Econ 27:167-186

Scheel H (2001) Undesirable outputs in efficiency valuations. Eur J Oper Res 132:400-410

Shaik S, Helmers GA, Langemeier MR (2002) Direct and indirect shadow price and cost estimates of nitrogen pollution abatement. J Agric Resour Econ 27:420-432

Tyteca D (1996) On the measurement of the environmental performance of firms - a literature review and a productive efficiency perspective. J Environ Manage 46:281-308

Tyteca D (1997) Linear programming models for the measurement of environmental performance of firms -concepts and empirical results. J Prod Anal 8:183-197

Wossink A, Gardebroek C (2006) Environmental policy uncertainty and marketable permit systems: The Dutch phosphate quota program. Am J Agric Econ 88:16-27 